\title{
悬 \\ Prevalência de anticorpos anti-Neospora caninum em vacas leiteiras procedentes da agricultura familiar no estado de Pernambuco
}

\author{
[Prevalence of anti-Neospora caninum antibodies in dairy cows deriving from family-based \\ farming in the Brazilian state of Pernambuco]
}

\section{"Artigo Científico/Scientific Article"}

\author{
Carlos André Barbosa França ${ }^{1}$, Adrianne Mota Alcântara ${ }^{2}$, Pollyanne Raysa Fernandes \\ Oliveira $^{2 *}$, Antonio Fernando Barbosa Batista Filho ${ }^{1}$, Jonas Melo Borges ${ }^{1}$, \\ Marlos José Portela Rêgo ${ }^{1}$, Rinaldo Aparecido Mota ${ }^{2,3}$, José Wilton Pinheiro Junior ${ }^{3}$
}

\footnotetext{
${ }^{1}$ Programa de Pós-Graduação em Sanidade de Ruminantes, Unidade Acadêmica de Garanhuns, Garanhuns-PE, Brasil. ${ }^{2}$ Programa de Pós-Graduação em Biociência Animal, Universidade Federal Rural de Pernambuco, Recife-PE, Brasil. ${ }^{3}$ Departamento de Medicina Veterinária, Universidade Federal Rural de Pernambuco, Recife-PE, Brasil.

*Autora para correspondência/Corresponding author: E-mail: pollyanne raysa@ hotmail.com
}

\section{Resumo}

Objetivou-se com este estudo determinar a prevalência de anticorpos anti-Neospora caninum e analisar os fatores de risco associados à infecção em vacas leiteiras da agricultura familiar na região Intermediária de Caruaru, estado de Pernambuco. Foram coletadas amostras de sangue de 341 vacas leiteiras, procedentes de 25 propriedades rurais, em 16 municípios. As amostras obtidas foram submetidas à técnica de Reação de Imunofluorescência Indireta (RIFI). Para a análise dos fatores de risco foi aplicado um questionário investigativo objetivo sobre o manejo higiênico-sanitário e reprodutivo. Os dados foram analisados por regressão logística, considerando como variável dependente o resultado sorológico. A prevalência de anticorpos IgG anti- $N$. caninum foi 18,2\% (62/341) em vacas leiteiras, com $80 \%$ (20/25) de propriedades com animais positivos. Embora este estudo não tenha mostrado evidências de que o número de cães estava associado a altos níveis de anticorpos IgG anti- $N$. caninum, uma maior prevalência foi observada naquelas propriedades que apresentavam cães em contato com as vacas leiteiras $(20,1 \%-48 / 238)$, carcaças jogadas no próprio campo sem nenhum cuidado higiênico-sanitário $(28,9 \%$ - 47/225) e não realizavam quarentena (19,7\%-56/284). Esses resultados evidenciam que vacas leiteiras da região Intermediária de Caruaru estão expostas a $N$. caninum.

Palavras-chave: bovinocultura; neosporose; diagnóstico; prevenção.

\begin{abstract}
This study aimed to determine the prevalence of anti-Neospora caninum antibodies and to analyze the risk factors associated with infection in dairy cows from family farming in the Caruaru Intermediate region, state of Pernambuco. Blood samples were collected from 341 dairy cows derived from 25 rural properties in 16 municipalities. The samples were submitted to the Indirect Immunofluorescent Assay Technique (IFAT). For analysis of risk factors, an objective investigative questionnaire on hygienic-sanitary and reproductive management was used. Data were analyzed by logistic regression, considering the serological result as a dependent variable. The prevalence of anti-N. caninum IgG antibodies was $18.2 \%(62 / 341)$ in dairy cows, with $80 \%$ (20/25) outbreaks. Although this study did not show evidence that the number of dogs was associated with high levels of anti- $N$. caninum $\operatorname{IgG}$ antibodies, a higher prevalence was observed in those properties that had dogs in contact with dairy cows $(20.1 \%$ - 48 / 238), carcasses thrown in the field without any hygienic-sanitary care $(28.9 \%-47 / 225)$, and no quarantine $(19.7 \%-56 / 284)$. These results show that dairy cows in the Caruaru Intermediate region are exposed to $N$. caninum.
\end{abstract}

Keywords: cattle farming; neosporosis; diagnosis; prevention. 


\section{Introdução}

A agricultura familiar é responsável por grande parte dos alimentos consumidos no Brasil (IBGE, 2017) e dentre as diversas atividades produtivas realizadas por esses agricultores, a bovinocultura destaca-se por ter uma expressiva participação na economia do país e nas pequenas propriedades, principalmente, aquelas localizadas no interior nordestino, mesmo sob as adversidades econômicas, climáticas, tecnológicas e de assistência técnica (Delgado e Bergamasco, 2017).

Entende-se por agricultor familiar e empreendedor familiar rural aquele que pratica atividade no meio rural, atendendo, simultaneamente, aos seguintes requisitos: não detenha área superior a quatro módulos fiscais, utilize predominantemente mão-de-obra da própria família, assim como gerencie a propriedade ou empreendimento rural, e obtenha um percentual mínimo de sua renda da atividade econômica desenvolvida no seu estabelecimento familiar (BRASIL, 2006).

Neospora caninum é um Apicomplexa causador da neosporose, uma das principais causas de abortamento na espécie bovina, com eficiente transmissão transplacentária. Durante a gestação, a invasão e proliferação de $N$. caninum, em uma primo-infecção ou em uma recrudescência de uma infecção latente, são eventos cruciais na patogênese (Dubey al., 2006). Estudos demonstram que a enfermidade encontrase disseminada nos diversos continentes e países: América do Norte (Sanderson et al., 2000; VanLeeuwen et al., 2010; Rábago-Castro et al., 2017), América do Sul (Bañales et al., 2006) e continente Africano (Njiro et al., 2011; Lucchese et al., 2016; Derdour et al., 2017). No Brasil, a prevalência apresenta uma variação de $2,45 \%$ no Mato Grosso (Rodrigues et al., 2016) a 97,2\% em Minas Gerais (Guedes et al., 2008).

Além dos bovinos e de seus hospedeiros definitivos, os canídeos (Dubey et al., 1988; Thilsted et al., 1989), há relatos da detecção de anticorpos anti- $N$. caninum e/ou da infecção pelo parasito em uma variedade de espécies animais de produção, a exemplo os bubalinos (Oliveira et al., 2018), caprinos (Dubey et al., 1992), ovinos (García-Sánchez et al., 2020), suínos (Feitosa et al., 2014), dentre outros (Dubey e Schares, 2011).

A ocorrência da neosporose em rebanhos bovinos ocasiona inúmeros prejuízos à atividade produtiva, sendo a enfermidade responsável por abortamentos, diminuição do desempenho reprodutivo e queda na produção de leite, ocorrendo paralelamente o aumento dos custos com tratamento dos animais infectados (Lindsay et al., 1999). Apesar de sua importância para a bovinocultura, são escassos os estudos sobre o real impacto econômico da doença no Brasil. De acordo com revisão realizada por Reichel et al. (2013), os prejuízos para a indústria de lacticínio nos Estados Unidos são estimados em US\$ 546,3 milhões de dólares por ano; já no Brasil a estimativa é de US\$ 51,3 milhões de dólares em bovinos de leite.

Devido à falta de estudos com rebanhos bovinos da agricultura familiar e os prejuízos que a infecção por este parasito pode ocasionar para a renda dessas famílias, objetivou-se com este estudo determinar a prevalência de anticorpos anti- $N$. caninum e analisar os fatores de risco associados à infecção em vacas leiteiras de agricultura familiar procedentes da região Intermediária de Caruaru, estado de Pernambuco.

\section{Material e Métodos}

\section{Área de estudo}

A região Intermediária de Caruaru está localizada no Agreste do estado de Pernambuco e é composta por 16 municípios (Alagoinha, Belo Jardim, Bezerros, Brejo da Madre de Deus, Cachoeirinha, Capoeiras, Caruaru, Gravatá, Jataúba, Pesqueira, Poção, Riacho das Almas, Sanharó, São Bento do Una, São Caetano e Tacaimbó) (IBGE, 2019).

Possui uma área de $6625,926 \mathrm{~km}^{2}$ e uma população de 755.091 habitantes (IBGE, 2010). Abrange municípios de importância inter-regional para o comércio de animais de produção, a partir de feiras de gado. A prática envolve diversos municípios, dos quais se destacam Caruaru, Cachoeirinha e Capoeiras.

\section{Amostragem}

Foi realizado um estudo transversal por amostragem não probabilística por conveniência em 25 propriedades rurais de agricultura familiar, em 16 municípios. As propriedades visitadas para esta pesquisa foram escolhidas, com base nos cadastros dos escritórios municipais do Instituto Agronômico de Pernambuco - IPA

Para a determinação do número de animais foi admitida uma prevalência de $31,7 \%$ (Silva et al., 2008), com o intervalo de confiança de $95 \%$ e 
erro estatístico de 5\% (Thrusfield, 2004), o que determinou uma amostragem mínima de 333 animais. O número de vacas leiteiras em cada propriedade foi calculado de acordo com os parâmetros de prevalência, intervalo de confiança e erro estatístico supracitado. No total foram coletadas 341 amostras de sangue de vacas leiteiras em idade reprodutiva.

\section{Coleta das amostras}

As amostras de sangue em vacas leiteiras foram coletadas por venopunção na região coccígea em tubos do tipo Vacutainer®. Os tubos devidamente identificados foram encaminhados para o laboratório e centrifugados por 10 minutos a $1800 \times \mathrm{g}$ para obtenção do soro. De cada amostra foram retiradas duas alíquotas de soro, que foram identificadas e mantidas à $-20^{\circ} \mathrm{C} \mathrm{em}$ tubos de polipropileno de $1,5 \mathrm{~mL}$, até o momento da análise sorológica.

\section{Teste sorológico}

Para detecção dos anticorpos IgG anti- $N$. caninum utilizou-se a técnica da Reação de Imunofluorescência Indireta (RIFI), inicialmente, foi realizada a sensibilização das lâminas com suspensões de taquizoítos de $N$. caninum, cepa NC-1 (10 ${ }^{7}$ taquizoítos $\left./ \mathrm{mL}\right)$, distribuídas em lâminas de vidro $(10 \mu \mathrm{L} /$ poço $)$, secas em temperatura ambiente e em seguida fixadas com acetona refrigerada. Os soros dos animais foram diluídos em solução salina tamponada com fosfato (PBS), considerando como ponte de corte 1:200 (Dubey e Lindsay, 1996), além disso, um anticorpo secundário anti-IgG bovino conjugado com fluoresceína, (Sigma-Aldrich, Saint Louis, MO, EUA) foi utilizado em uma diluição de 1:300.

Foram consideradas amostras positivas aquelas que apresentaram fluorescência periférica total dos taquizoítos, em $50 \%$ ou mais dos taquizoítos presentes em cada poço (Paré et al., 1995; Dubey e Lindsay, 1996). Nesse processo, foram utilizados soros de referência, identificados como controle positivo e negativo em cada lâmina (Dubey et al., 1988).

Fatores de risco associados à infecção por Neospora caninum

Nas propriedades foi realizada a aplicação do questionário investigativo aos produtores, constituído por perguntas objetivas, referentes às características do manejo produtivo, reprodutivo e sanitário, a fim de identificar possíveis fatores de risco. A aplicação dos questionários foi realizada por um único entrevistador.

\section{Análise estatística}

Para a análise descritiva dos dados, utilizou-se dispersão das frequências absoluta e relativa. Para o estudo dos fatores de risco associados à infecção por $N$. caninum foi realizada uma análise univariada das variáveis de interesse pelo teste de Qui-quadrado de Pearson ou Exato de Fisher, quando necessário, e posteriormente uma análise de regressão logística, considerando como variável dependente o resultado obtido na sorologia (positivo ou negativo). As variáveis independentes ou explanatórias consideradas no modelo foram aquelas que apresentaram significância estatística $<0,20$. Essa probabilidade foi estipulada para que possíveis fatores de risco do evento não fossem excluídos da análise (Hosmer e Lemeshow, 1989). O programa EpiInfo $^{\mathrm{TM}} 7$ foi utilizado para a execução dos cálculos estatísticos e o nível de significância adotado foi de $5,0 \%$.

\section{Georeferrenciamento}

Para a elaboração do mapa de prevalência, foram obtidas as coordenadas geográficas com a utilização do GPS (Global Positioning Sistem). O mapa foi elaborado com o software QuantumGIS® 2.14.0.

\section{Resultados}

A prevalência dos anticorpos anti- $N$. caninum foi $18,2 \%(62 / 341)$ em vacas leiteiras procedentes de agricultores familiares, com $80 \%$ (20/25) de propriedades com animais positivos (Figura 1). A distribuição da prevalência por propriedade e município encontra-se disposta na Tabela 1. Neste estudo não foi confirmado nenhum fator de risco associado à infecção por $N$. caninum (Tabela 2).

\section{Discussão}

Este é o primeiro estudo epidemiológico sobre a prevalência dos anticorpos anti- $N$. caninum realizado no estado de Pernambuco com vacas leiteiras da agricultura familiar. A prevalência identificada neste estudo é semelhante à média $(23,65 \%)$ registrada em estudos sorológicos com bovinos leiteiros, utilizando a RIFI com um ponto de corte de 1:200, no Nordeste brasileiro, no período de 2005 a 2014 
(Silva et al., 2008; Teixeira et al., 2010; Amaral et al., 2012; Sousa et al., 2012; Magalhães et al., 2014; Silva et al., 2014; Oliveira et al., 2018).

Ao analisar o número de propriedades com animais positivos, observou-se que $80,0 \%(20 / 25)$ das propriedades apresentaram ao menos um animal positivo. Este resultado é preocupante do ponto de vista epidemiológico, uma vez que na área do estudo em questão existe uma grande comercialização de animais entre propriedades e nas feiras de gado, o que pode contribuir para a disseminação do patógeno.
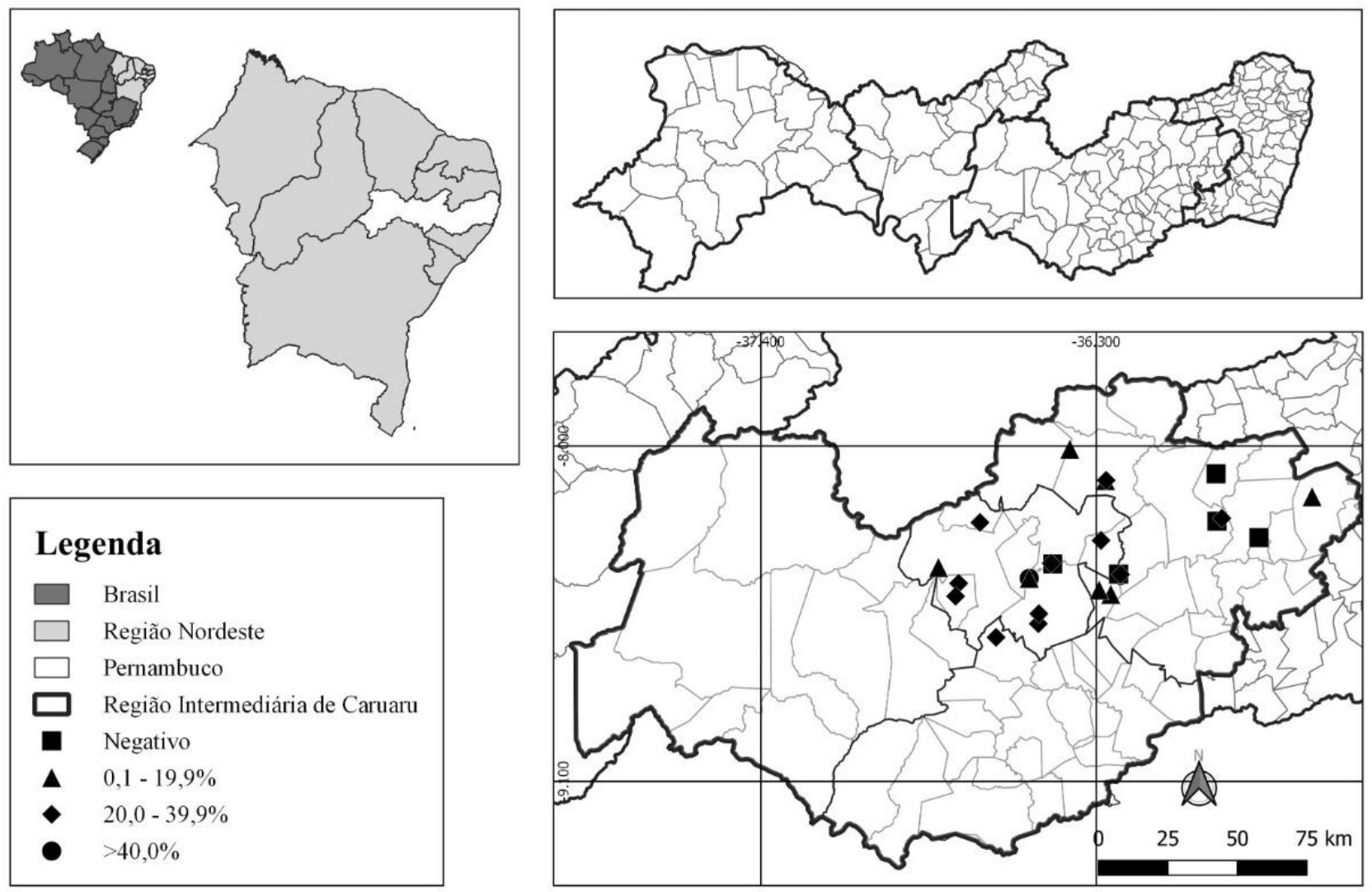

Figura 1. Distribuição da prevalência de anticorpos IgG anti-Neospora caninum em rebanhos bovinos leiteiros da agricultura familiar da região Intermediária de Caruaru, estado de Pernambuco, Brasil.

Em relação à distribuição da prevalência nas propriedades estudadas, constatou-se uma variação de $0,0 \%$ a $43,7 \%$. Essa variação pode estar relacionada aos diferentes manejos higiênico-sanitários adotados nas propriedades visitadas, uma vez que diferentes fatores podem influenciar na prevalência entre rebanhos, tais como: sistema de criação, armazenamento de alimentos, presença de cães domésticos e silvestres, tipo de água fornecida, presença de roedores, acesso de cães a fetos e restos placentários deixados a campo. Estudo realizado em propriedades de bovinos leiteiros no sul do Brasil também evidenciou uma variação elevada entre as prevalências das propriedades, indicando que as práticas de manejo e características das fazendas podem influenciar na exposição dos animais à infecção por $N$. caninum (Corbellini et al., 2006).
Ao avaliar os fatores de riscos envolvidos na infecção, não foi identificada nenhuma associação possível. Contudo, observou-se uma maior prevalência naquelas propriedades que apresentavam cães em contato com as vacas leiteiras $(20,1 \%$ - 48/238), carcaças jogadas no próprio campo sem nenhum cuidado higiênicosanitário $(28,9 \%$ - 47/225) e a não realização de quarentena $(19,7 \%$ - 56/284).

Destaca-se que nas 05 (cinco) propriedades com $0,0 \%$ de prevalência não existia histórico de abortamento. Em contrapartida, a propriedade que apresentou maior prevalência $(43,7 \%$ - $7 / 16)$ apresentava histórico de abortamento recente sendo relatado pelo proprietário que fetos e restos placentários eram deixados no campo e que os cães tinham acesso a essa pastagem.

Os fatores de risco associados à infecção por $N$. caninum em bovinos são: presença de cães nas propriedades (Bartels et al., 1999; Hobson et 
al., 2005; VanLeeuwen et al., 2010; Sousa et al., 2012; Portocarrero et al., 2015); presença de canídeos silvestres (Sousa et al., 2012; Asmare et al., 2013); presença de aves, alimentação com silagem de milho (Bartels et al., 1999); rebanho com maiores números de animais (Aguiar et al., 2006; Asmare et al., 2013; Portocarrero et al., 2015); sistema de criação (Silva et al., 2008); presença de restos placentários, anexos fetais e fetos abortados nos pastos (Sousa et al., 2012; Portocarrero et al., 2015).

Apesar de o abortamento ser um dos principais problemas ocasionados por este agente, outros distúrbios reprodutivos também são atribuídos a $N$. caninum, como a retenção de placenta, a repetição de cio, a distorcia e o prolapso uterino ou vaginal (Asmare et al., 2012). Embora os distúrbios reprodutivos causem prejuízos econômicos, por vezes, visíveis, o agente em questão traz a possibilidade do surgimento do animal persistentemente infectado (PI), que pode torna-se imperceptível aos olhos do produtor. A alta taxa de infecção congênita e a elevada taxa de sobrevivência de bezerros PIs contribuem para a manutenção do patógeno no rebanho (Paré et al., 1996), esses descendentes de mães soropositivas não devem ser mantidos no rebanho, pois podem gerar outros animais soropositivos por várias gerações (Peter, 2000; Fioretti et al., 2003).

Tabela 1. Prevalência de anticorpos IgG anti-Neospora caninum por animal e propriedades da agricultura familiar, pertencentes à região Intermediária de Caruaru, estado de Pernambuco, Brasil.

\begin{tabular}{|c|c|c|c|c|c|}
\hline Município & $\begin{array}{c}\mathbf{N}^{\circ} \text { da } \\
\text { propriedade }\end{array}$ & $\begin{array}{c}\text { Bovinos } \\
\text { Positivos/propriedade/ } \\
\text { P }(\%)\end{array}$ & $\begin{array}{c}\text { Municípios P } \\
(\%)\end{array}$ & $\begin{array}{l}\text { Número de } \\
\text { propriedades } \\
\text { com animais } \\
\text { positivos }\end{array}$ & $\begin{array}{c}\text { Casos de } \\
\text { abortamentos }\end{array}$ \\
\hline \multirow{2}{*}{ Alagoinha } & 1 & $2 / 6(33,3)$ & \multirow{2}{*}{26,7} & \multirow[t]{2}{*}{ 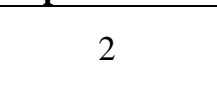 } & Não \\
\hline & 2 & $2 / 9(22,2)$ & & & Não \\
\hline \multirow{2}{*}{ Sanharó } & 3 & $1 / 11(9,1)$ & \multirow{2}{*}{29,6} & \multirow{2}{*}{2} & Sim \\
\hline & 4 & $7 / 16(43,7)$ & & & Sim \\
\hline \multirow{2}{*}{ São Caetano } & 5 & $0 / 15(0,0)$ & \multirow{2}{*}{18,4} & \multirow{2}{*}{1} & Não \\
\hline & 6 & $7 / 23(30,4)$ & & & Sim \\
\hline \multirow{2}{*}{ Cachoeirinha } & 7 & $2 / 20(10,0)$ & \multirow{2}{*}{7,3} & \multirow{2}{*}{2} & Não \\
\hline & 8 & $1 / 21(4,7)$ & & & Sim \\
\hline Capoeiras & 9 & $5 / 20(25,0)$ & 25,0 & 1 & Sim \\
\hline \multirow{2}{*}{ São Bento do Una } & 10 & $4 / 19(21,0)$ & \multirow{2}{*}{25,0} & \multirow{2}{*}{2} & Sim \\
\hline & 11 & $5 / 17(29,4)$ & & & Sim \\
\hline Pesqueira & 12 & $1 / 16(6,2)$ & 6,2 & 1 & Sim \\
\hline Poção & 13 & $2 / 10(20,0)$ & 20,0 & 1 & Não \\
\hline Tacaimbó & 14 & $5 / 15(33,3)$ & 33,3 & 1 & Sim \\
\hline \multirow{2}{*}{ Belo Jardim } & 15 & $0 / 12(0,0)$ & \multirow{2}{*}{13,3} & \multirow{2}{*}{1} & Não \\
\hline & 16 & $4 / 18(22,2)$ & & & Sim \\
\hline \multirow{2}{*}{ Brejo da Madre de Deus } & 17 & $3 / 17(17,6)$ & \multirow{2}{*}{21,4} & \multirow{2}{*}{2} & Não \\
\hline & 18 & $3 / 11(27,3)$ & & & Não \\
\hline Jataúba & 19 & $3 / 17(17,6)$ & 17,6 & 1 & Não \\
\hline \multirow{2}{*}{ Caruaru } & 20 & $1 / 5(20,0)$ & \multirow{2}{*}{12,5} & \multirow{3}{*}{1} & Não \\
\hline & 21 & $0 / 3(0,0)$ & & & Não \\
\hline Bezerros & 22 & $0 / 8(0,0)$ & 0,0 & & Não \\
\hline \multirow{2}{*}{ Riacho das Almas } & 23 & $2 / 14(14,3)$ & \multirow{2}{*}{10,0} & \multirow{2}{*}{1} & Sim \\
\hline & 24 & $0 / 6(0,0)$ & & & Não \\
\hline Gravatá & 25 & $2 / 12(16,7)$ & 16,7 & 1 & Não \\
\hline Total & 25 & $42 / 341(18,2 \%)$ & $15 / 16(93,7 \%)$ & $20(80,0 \%)$ & \\
\hline
\end{tabular}

Neste estudo não foi possível confirmar que a ocorrência de abortamento foi devido à infecção exclusiva por $N$. caninum, visto que a infecção por outros agentes pode ocasionar este distúrbio reprodutivo. Desta forma, sugere-se a utilização de métodos diretos para a identificação do agente em espécimes biológicas, para confirmar a real participação de N. caninum nos casos de abortamento.

Paralelamente às medidas de identificação do agente relacionado ao distúrbio reprodutivo, é imprescindível a realização da quarentena, contudo, no presente estudo esta prática não foi observada em todas as propriedades avaliadas. 
Trata-se de uma medida que deve ser adotada como forma de controlar a neosporose bovina, visto que a recrudescência desta infecção é comum e pode levar esses animais a apresentarem distúrbios reprodutivos ou produzirem crias fracas, assim como a geração dos animais PIs. A recrudescência é comum durante a gestação de animais PIs, podendo ocasionar o nascimento de outros animais PIs ou provocar abortamentos por diversas vezes (Williams et al., 2009).

Tabela 2. Análise dos fatores de risco associados à infecção por Neospora caninum em rebanhos de vacas leiteiras pertencentes à agricultura familiar procedentes da região Intermediária de Caruaru, estado de Pernambuco, Brasil.

\begin{tabular}{|c|c|c|c|c|c|}
\hline \multirow[b]{2}{*}{ Variáveis } & \multirow[b]{2}{*}{$\mathbf{N}$} & \multirow{2}{*}{$\begin{array}{c}\text { SOROLOGIA } \\
\text { Reagente }\end{array}$} & \multirow{2}{*}{$\begin{array}{c}\text { Valor } \mathbf{P} \\
\text { Análise univariada }\end{array}$} & \multirow{2}{*}{$\begin{array}{c}\text { Análise } \\
\text { multivariada OR } \\
\text { (I.C. 95\%) }\end{array}$} & \multirow[b]{2}{*}{ Valor $\mathbf{P}$} \\
\hline & & & & & \\
\hline \multicolumn{6}{|l|}{ Sistema de criação } \\
\hline Extensivo & 34 & $5(14,7 \%)$ & \multirow{2}{*}{$0,580^{(\mathbf{A})}$} & & \\
\hline Semi-intensivo & 307 & $57(18,5 \%)$ & & & \\
\hline \multicolumn{6}{|l|}{ Tamanho do rebanho } \\
\hline Até 10 animais & 20 & $3(15,5 \%)$ & \multirow{3}{*}{$0,562^{(\mathbf{A})}$} & & \\
\hline Entre 11 e 20 & 20 & $2(10,0 \%)$ & & & \\
\hline Acima de 20 & 301 & $57(18,9 \%)$ & & & \\
\hline \multicolumn{6}{|l|}{ Tipo de rebanho } \\
\hline Aberto & 192 & $39(20,3 \%)$ & \multirow{2}{*}{$0,247^{(\mathbf{A})}$} & & \\
\hline Fechado & 149 & $23(15,4 \%)$ & & & \\
\hline \multicolumn{6}{|l|}{ Realiza quarentena } \\
\hline Sim & 57 & $6(10,5 \%)$ & \multirow{2}{*}{$0,101^{(\mathbf{A})}$} & \multirow{2}{*}{$2,4(0,8-7,5)$} & \multirow{2}{*}{0,122} \\
\hline Não & 284 & $56(19,7 \%)$ & & & \\
\hline \multicolumn{6}{|l|}{ Suplementação mineral } \\
\hline Sim & 328 & $61(18,6 \%)$ & \multirow{2}{*}{$0,476^{(\mathbf{B})}$} & & \\
\hline Não & 13 & $1(7,7 \%)$ & & & \\
\hline \multicolumn{6}{|c|}{ Histórico de abortamento ${ }^{I}$} \\
\hline $\operatorname{Sim}$ & 205 & $42(20,5 \%)$ & \multirow{2}{*}{$0,415^{(\mathbf{A})}$} & \multirow{2}{*}{$1,4(0,6-3,1)$} & \multirow{2}{*}{0,414} \\
\hline Não & 108 & $18(16,6 \%)$ & & & \\
\hline \multirow{2}{*}{\multicolumn{6}{|c|}{$\begin{array}{l}\text { Cães em contato com as vacas } \\
\text { leiteiras }\end{array}$}} \\
\hline & & & & & \\
\hline Sim & 238 & $48(20,17 \%)$ & \multirow{3}{*}{$0,096^{(\mathbf{A})}$} & \multirow{2}{*}{$1,60(0,84-3,06)$} & \multirow{2}{*}{0,151} \\
\hline Não & 103 & $14(13,59 \%)$ & & & \\
\hline \multicolumn{5}{|c|}{$\begin{array}{l}\text { Destino das carcaças de } \\
\text { bovinos }\end{array}$} & \\
\hline Queimados & 225 & $178(79,11 \%)$ & & - & \\
\hline Enterrados & 85 & $73(85,88 \%)$ & & $1,60(0,80-3,20)$ & 0,178 \\
\hline Deixados a campo & 31 & $28(90,32 \%)$ & & $2,46(0,71-8,45)$ & 0,151 \\
\hline \multicolumn{6}{|c|}{ Observa cães na propriedade } \\
\hline Sim & 328 & $61(18,6 \%)$ & \multirow{2}{*}{$0,476^{(\mathbf{B})}$} & & \\
\hline Não & 13 & $1(7,7 \%)$ & & & \\
\hline Cria cães na proprieds & & & & & \\
\hline $\operatorname{Sim}$ & 227 & $40(17,6 \%)$ & & & \\
\hline Não & 114 & $22(19,3 \%)$ & $0,705^{(\mathrm{A})}$ & & \\
\hline
\end{tabular}

Na região Intermediária de Caruaru há uma prática cultural de feira de gado que contribui com a movimentação desses animais e, por consequência, de enfermidades. Neste contexto, a prática da quarentena é importante, pois novilhas de reposição mesmo que negativas no ato da compra, podem sofrer recrudescimento da infecção crônica durante a sua primeira gestação, o que facilita a disseminação de $N$. caninum (Rodríguez et al 2016).

Outro fator epidemiológico que deve ser ressaltado é o destino das carcaças de forma inadequada, fator observado em 48,0\% (12/25) das propriedades avaliadas e com animais sororreagentes. $\mathrm{O}$ acesso de cães a restos placentários e/ou fetos abortados favorece a continuação da cadeia de transmissão de $N$. caninum na propriedade, visto que os cães, ao ingerirem essas carcaças contaminadas com bradizoítos de $N$. caninum, se infectam e eliminam oocistos no meio ambiente, contaminando água e pastagens (VanLeeuwen et al., 2010; Sousa et al., 2012; Portocarrero et al., 2015). 


\section{Conclusão}

Esses resultados evidenciam que vacas leiteiras da região Intermediária de Caruaru estão expostas a $N$. caninum. $\mathrm{O}$ agente em questão pode ocasionar prejuízos econômicos, uma vez que pode ocasionar abortamento e repetição do estro. Deste modo, torna-se imprescindível a inclusão de medidas de prevenção e controle, tais como: realização de testes sorológicos de forma rotineira para identificar eventuais animais PI e descarte de animais positivos. Contudo, do ponto de vista econômico, o descarte pode ser inviável, em casos onde se constata uma prevalência elevada, sendo aconselhável um descarte gradativo. Um outro fator importante, é o controle do ingresso de bovinos na propriedade, a partir de teste de diagnóstico, visando impedir a entrada de animais infectados no rebanho. Do ponto de vista epidemiológico, é também importante controlar a população canina, já que estes eliminam no ambiente os oocistos, contaminando assim água e alimentos.

\section{Conflito de Interesse}

Os autores declaram não existir conflito de interesse.

\section{Comitê de Ética}

O projeto foi aprovado pelo Comitê de Ética no Uso de Animais da Universidade Federal Rural de Pernambuco, com licença n ${ }^{\circ}$ 058/2014.

\section{Referências}

Aguiar, D.M.; Cavalcante, G.T.; Rodrigues, A.A.R.; Labruna, M.B.; Camargo, L.M.A.; Camargo, E.P.; Gennairi, S.M. Prevalence of anti-Neospora caninum antibodies in cattle and dogs from Western Amazon, Brazil, in association with some possible risk factors. Veterinary Parasitology, 142 (1-2): 71-77, 2006.

Amaral, R.L.G.; Silva, L.B.G.; Pinheiro Junior, J.W.; Souza Neto, O.L.; Leal, C.A.S.; Porto, W.J.N.; Barbosa, J.M.P.; Mota, R.A. Neospora caninum em bovinos em matadouros de Pernambuco e Alagoas. Pesquisa Veterinária Brasileira, 32 (10): 963-966, 2012.

Asmare, K.; Regassa, F.; Robertson, L.J.; Martin, A.D.; Skjerve, E. Reproductive disorders in relation to Neospora caninum, Brucella spp. and bovine viral diarrhea virus serostatus in breeding and dairy farms of central and
Southern Ethiopia. Epidemiology and Infection, 141(8): 1772-1780, 2012.

Asmare, K.; Regassa, F.; Skjerve, E. Soroprevalence of Neospora caninum and associated risk factors in intensive or semiintensively managed dairy and breeding cattle of Ethiopia. Veterinary Parasitology, 193(1-3): 85-94, 2013.

Bañales, P.; Fernandes, L.; Repiso, M.V.; Gil, A.; Dargatz, D.A.; Osawa, T. A Nationwide survey on seroprevalence of Neospora caninum infection in beef cattle in Uruguay. Veterinary Parasitology, 139(1-3): 15-20, 2006.

Bartels, C.J.M.; Wouda, W.; Schukken, Y.H. Risk factors for Neospora caninum-associated abortion storms in dairy herds in The Netherlands (1995 to 1997).

Theriogenology, 52(2): 247-257, 1999.

BRASIL. Ministério da Agricultura, Pecuária e Abastecimento. Lei 11.326, de 24 de julho de 2006. Disponível em: <http://www.planalto.gov.br/ccivil_03/_Ato2 004-2006/2006/Lei/L11326.htm>. Acesso em: 01 set. 2020.

Corbellini, L.G.; Smith, D.R.; Pescador, C.A.; Schmtz, M.; Correa, A.; Steffen, D.J.; Driemeier, D. Herd-level risk factors for Neospora caninum soroprevalence in dary farms in sourthern Brazil. Preventive Veterinary Medicine, 74(2-3): 130-141, 2006.

Delgado, G.C.; Bergamasco, $\quad$ S.M.P.P. Agricultura familiar brasileira: desafios e perspectivas de futuro. $1^{\text {a }}$ ed. Brasília: Ministério do Desenvolvimento Agrário, 2017. 470p.

Derdour, S.Y.; Hafsi, F.; Azzag, N.; Tennah, S.; Laamari, A.; China, B.; Ghalmi, F. Prevalence of the main infectious causes of abortion in dairy cattle in Algeria. Journal of Veterinary Research, 61(3): 337-343, 2017.

Dubey, J.P.; Acland, H.M.; Hamir, A.N. Neospora caninum (Apicomplexa) in a stillborn goat. The Journal of Parasitology, 78(3): 532-534, 1992.

Dubey, J.P.; Buxton, D.; Woda, W. Pathogenesis of bovine neosporosis. Journal of Comparative Pathology, 134(4): 267-289, 2006.

Dubey, J.P.; Carpenter, J.L.; Speer, C.A.; Topper, M.J.; Uggla, A. Newly recognized fatal protozoan disease of dogs. Journal of the 
American Veterinary Medical Association, 194(9): 1269-1285, 1988.

Dubey, J.P.; Lindsay, D.S. A review of Neospora caninum and neosporosis. Veterinary Parasitology, 67(1-2): 1-59, 1996.

Dubey, J.P.; Schares, G. Neosporosis in animals the last five years. Veterinary Parasitology, 180(1-2): 90-108, 2011.

Feitosa, T.F; Vilela, V.L.; Melo, L.R.; Almeida Neto, J.L.; Souto, D.V.; Morais, D.F.; Athayde, A.C.; Azevedo, S.S.; Pena, H.F. Toxoplasma gondii and Neospora caninum in slaughtered pigs from Northeast, Brazil. Veterinary Parasitology, 202(3-4): 305-309, 2014.

Fioretti, D.P.; Pasquali, P.; Diaferia, M.; Mangili, V.; Rosignoli, L. Neospora caninum infection and congenital transmission: Serological and parasitological study of cows up to the fourth gestation. Journal of Veterinary Medicine Series B, 50(8): 399404, 2003.

García-Sánchez, M.; Moreno-Gonzalo, J.; González-Warleta, M.; Mezo, M.; OrtegaMora, L.M.; Regidor-Cerrillo, J. Isolation and genetic characterization of Neospora caninum from naturally infected sheep. Veterinary Parasitology, 280: 1-5, 2020.

Guedes, M.H.P.; Guimarães, A.M.; Rocha, C.M.B.M.; Hirsch, C. Freqüência de anticorpos anti-Neospora caninum em vacas e fetos provenientes de municípios do sul de Minas Gerais. Revista Brasileira de Parasitologia Veterinária, 17(4): 189-194, 2008.

Hobson, J.C.; Duffield, T.F.; Kelton, D.; Lissemore, K.; Hietala, S.K.; Leslie, K.E.; McEwen, B.; Perigine, A. S. Risk factors associated with Neospora caninum abortion in Ontario Holstein dairy herds. Veterinary Parasitology, 127(3-4): 177-188, 2005.

Hosmer D.W.; Lemeshow S. Applied logistic regression. New York: John Wiley \& Sons, 1989. 241p.

Instituto Brasileiro de Geografia e Estatística IBGE. Censo - Panorama das cidades. $2010 . \quad$ Disponível em: $<$ https://cidades.ibge.gov.br/brasil/pe/panora ma>. Acesso em 01 set. 2020.

Instituto Brasileiro de Geografia e Estatística IBGE. Censo Agropecuário. 2017. Disponível em: $<$ https://sidra.ibge.gov.br/pesquisa/censo- agropecuario/censo-agropecuario-2017>.

Acesso em 01 set. 2020.

Instituto Brasileiro de Geografia e Estatística IBGE. Malhas Digitais, PernambucoMicrorregiões. 2019. Disponível em: $<$ https://portaldemapas.ibge.gov.br/portal.php \#mapa222707>. Acesso em 01 set. 2020.

Lindsay, D.S.; Dubey, J.P.; Duncan, R.B. Confirmation that the dog is a definitive host for Neospora caninum. Veterinary Parasitology, 82(4): 327-333, 1999.

Lucchese, L.; Benkirane, A.; Hakimi, I.; El Idrissi, A.; Natale, A. Seroprevalence study of the main causes of abortion in dairy cattle in Morocco. Veterinaria Italiana, 52(1): 1319, 2016.

Magalhães, V.C.S.; Oliveira, U.V.; Costa, S.C.L.; Santos, I.A.; Pereira, M.J.S.; Munhoz, A.D. Transmission paths of Neospora caninum in a dairy herd of crossbred cattle in the northeast of Brazil. Veterinary Parasitology, 202(3-4): 257-268, 2014.

Njiro, S.M.; Kidanemariam, A.G.; Tsotetsi, A.M.; Katsande, T.C.; Mnisi, M.; Lubisi, B.A.; Potts, A.D.; Baloyi, F.; Moyo, G.; Mpofu, J.; Kalake, A.; Williams, R. A study of some infectious causes of reproductive disorders in cattle owned by resource-poor farmers in Gauteng Province, South Africa. Journal of the South African Veterinary Association, 82(4): 213-218, 2011.

Oliveira, P.R.F.; Soares, L.B.F.; Borges, J.M.; Mota, R.A.; Pinheiro Junior, J.W. Prevalence and associated factors with Neospora caninum infection in female water buffaloes (Bubalus bubalis) from Pernambuco, Brazil. Revista Brasileira de Parasitologia Veterinária, 27(4): 439-445, 2018.

Oliveira, R.P.; Soares, N.M.; Silva, J.G.; Andrade, M.R.; Lira, N.S.C.; Farias, M.P.O.; Mota, R.A. Occurrence of anti-Neospora caninum antibodies in cattle in the dairy farming region of the State of Piauí, Brazil. Revista Brasileira de Parasitologia Veterinária, 27(4): 589-592, 2018.

Paré, J.; Hietala, S.K.; Thurmond, M.C. Congenital Neospora caninum in dairy cattle and associated calfhood mortality. Canadian Journal of Research, 60(2): 133-139, 1996.

Paré, J.; Hietala, S.K.; Thurmond, M.C. Interpretation of an Indirect Fluorescent Antibody Test for Diagnosis of Neospora sp. Infection in Cattle. Journal of Veterinary 
Diagnostic Investigation, 7(2): 273-275, 1995.

Peter, A.T. Abortions in dairy cows: New insights and economic impact. Advances in Dairy Technology, 12: 233-244, 2000.

Portocarrero, C.M.; Pinedo, R.V.; Falcón, N.P.; Chávez, A.V. Factores de riesgo asociados a la seroprevalencia de Neospora caninum en bovinos naturalmente infectados en la Ceja de Selva de Oxapampa, Perú. Revista de Investigaciones Veterinarias del Perú, 26(1): 119-126, 2015.

Rábago-Castro, J.L.; Jasso-Obregón, J.O.; Zertuche-Rodríguez, J.L.; Sánchez-Martínez, J.G.; Loredo-Osti, J.; Domínguez-Muñoz, M.A. Detection of Neospora caninum antibodies in beef cattle in Tamaulipas, Mexico. Case report. Austral Journal of Veterinary Sciences, 49(3): 205-207, 2017.

Reichel, M.P.; Ayanegui-Alcérreca, M.A.; Gondim, L.F.P.; Ellis, J.T. What is the global economic impact of Neospora caninum in cattle - The billion dollar question. International Journal for Parasitology, 43(2): 133-142, 2013.

Rodrigues, R.S.; Igarashi, M.; Muraro, L.S.; Gomes, A.H.B.; Aguiar, D.M.; Pacheco, T.A.; Okano, W.; Barro, M.P.; Santos, M.D. Ocorrência de anticorpos anti-Neospora caninum em fêmeas e fetos da espécie bovina do município de Nossa Senhora do Livramento, Mato Grosso. Semina: Ciências Agrárias, 37(6): 4161-4166, 2016.

Rodríguez, A.M.; Maresca, S.; Cano, D.B.; Armendano, J.I.; Combessies, G.; LopézValiente, S.; Odriozola, E.R.; Späth, E.J.L.; Odeón, A.C.; Campero, C.M.; Moore, D.P. Frequency of Neospora caninum infections in beef cow-calf operations under extensive management. Veterinary Pathology, 219: 40-43, 2016.

Sanderson, M.W.; Gay, J.M.; Baszler, T.V. Neospora caninum seroprevalence and associated risk factors in beef cattle in the northewestern United States. Veterinary Parasitology, 90(1-2): 15-24, 2000.
Silva, J.G.; Guerra, N.R.; Melo, R.P.B.; Albuquerque, P.P.F.; Alves, L.C.; Mota, R.A. Ocorrência de anticorpos IgG anti-Neospora caninum em vacas leiteiras no estado de Pernambuco, Brasil. Ciência Veterinária nos Trópicos, 17(1-2): 30-35, 2014.

Silva, M.I.S.; Almeida, M.A. O.; Mota, R.A.; Pinheiro Junior, J.W.; Rabelo, S.S.A. Fatores de riscos associados à infecção por Neospora caninum em matrizes bovinas leiteiras em Pernambuco. Ciência Animal Brasileira, 9(2): 455-461, 2008.

Sousa, M.E.; Porto, W.J.N.; Albuquerque, P.P.F.; Souza Neto, O.L.; Faria, E.B.; Pinheiro Junior, J.W.; Mota, R.A. Seroprevalence and risk factors associated with infection by Neospora caninum of dairy cattle in the state of Alagoas, Brazil. Pesquisa Veterinária Brasileira, 32(10): 1009-1013, 2012.

Teixeira, W.C.; Uzêda, R.S.; Gondim, L.F.P.; Silva, M.I.S.; Pereira, H.M.; Alves, L.C.; Faustino, M.A.G. Prevalência de anticorpos anti-Neospora caninum (Apicomplexa: Sarcocystidae) em bovinos leiteiros de propriedades rurais em três microrregiões no estado do Maranhão. Pesquisa Veterinária Brasileira, 30(9): 729-734, 2010.

Thilsted, J.P.; Dubey, J.P. Abortos semelhantes à neosporose em um rebanho de gado leiteiro. Journal of Veterinary Diagnostic Investigation, 1(3): 205-209, 1989.

Thrusfield, M. Epidemiologia veterinária. $2^{\mathrm{a}}$ ed. São Paulo: Roca, 2004. 556p.

VanLeeuwen, J.A.; Haddad, J.P.; Dohoo, I.R.; Keefe, G.P.; Tiwairi, A.; Scott, H. M. Risk factors associated with Neospora caninum seropositivity in randomly sampled Canadian dairy cows and herds. Preventive Veterinary Medicine, 93(2-3): 129-138, 2010.

Williams, D.J.L.; Hartley, C.S.; Björkman, C.; Trees, J. Endogenous and exogenous transplacental transmission of Neospora caninum - how the route of transmission impacts on epidemiology and control of disease. Parasitology, 136(14): 1895-1900, 2009 . 